\title{
Transcriptional Regulation of the p53 Tumor Suppressor Gene in S-Phase of the Cell-Cycle and the Cellular Response to DNA Damage
}

\author{
David Reisman, ${ }^{1}$ Paula Takahashi, ${ }^{2}$ Amanda Polson, ${ }^{1}$ and Kristy Boggs ${ }^{3}$ \\ ${ }^{1}$ Department of Biological Sciences, University of South Carolina, Columbia, SC 29208, USA \\ ${ }^{2}$ Departamento de Genética, Faculdade de Medicina de Ribeirão Preto, Universidade de São Paulo, Ribeirão Preto, SP, Brazil \\ ${ }^{3}$ Department of Hematology-Oncology, St. Jude Children's Research Hospital, Memphis, TN 38105, USA
}

Correspondence should be addressed to David Reisman, reisman@biol.sc.edu

Received 3 April 2012; Revised 20 June 2012; Accepted 21 June 2012

Academic Editor: Rolf J. Craven

Copyright (C) 2012 David Reisman et al. This is an open access article distributed under the Creative Commons Attribution License, which permits unrestricted use, distribution, and reproduction in any medium, provided the original work is properly cited.

\begin{abstract}
The $p 53$ tumor suppressor induces the transcription of genes that negatively regulate progression of the cell cycle in response to DNA damage or other cellular stressors and thus participates in maintaining genome stability. Numerous studies have demonstrated that $p 53$ transcription is activated before or during early S-phase in cells progressing from $\mathrm{G}_{0} / \mathrm{G}_{1}$ into $\mathrm{S}$-phase through the combined action of two DNA-binding factors RBP-J $\kappa$ and C/EBP $\beta-2$. Here, we review evidence that this induction occurs to provide available $p 53$ mRNA in order to prepare the cell for DNA damage in S-phase, this ensuring a rapid response to DNA damage before exiting this stage of the cell cycle.
\end{abstract}

\section{Introduction}

p53 is a DNA-binding transcription factor that activates genes responsible for a cell-cycle checkpoint or apoptosis after exposure to ionizing radiation, UV light, or other DNAdamaging agents [1-3]. The $p 53$ protein is induced both in terms of its abundance and its activity in response to DNA damage. Increased levels of $p 53$ protein are largely due to increased stability of the protein that is regulated through the loss of association with the MDM2 protein [1-3]. In normal cells where $p 53$ is found at very low levels, $p 53$ is present in a complex with MDM2 which targets $p 53$ for degradation through the ubiquitin pathway [4].

Activation of $p 53$ has been proposed to occur through a number of mechanisms which include phosphorylation, dephosphorylation by protein serine/threonine phoshatase- 1 [5], acetylation by the transcriptional coactivator p300/CBP [6], and induced conformational changes mediated by the prolyl isomerase Pin1 [7-10]. The increase in the level of active $p 53$ protein leads to an inhibition of entry into Sphase or the induction of apoptosis $[2,11,12]$. Thus, the loss or inactivation of p53 results in the loss of cell-cycle arrest or apoptosis after DNA damage or physiologic stresses. This loss, seen in many human cancers, has been proposed to lead to increased genetic instability, increased accumulation of mutations, and ultimately oncogenesis.

Interestingly, a number of studies indicate that tumorderived mutant forms of $p 53$, which are highly expressed in many cancers, while losing many of their DNA-damage checkpoint functions, function as active transforming genes $[13,14]$. These mutant $p 53$ genes serve as oncogenes that contribute to tumorigenesis [15-17].

Ever since Arnold Levine's group demonstrated that p53 expression was induced upon mitogenic stimulation of murine fibroblasts [18], and Reed et al. [19] demonstrated induced expression of $p 53$ upon mitogenic stimulation of human lymphocytes, and the molecular mechanism responsible for this regulation has remained unexplored. Similarly, an understanding of the biological significance of this induction has remained unclear. This is especially true in light of our current understanding of the role of $p 53$ as a suppressor of DNA synthesis and inducer of apoptosis. Although elevated levels of $p 53$ protein have been shown to lead to either growth arrest or apoptosis in response to 
DNA damage, it might seem anomalous that transcription of the $p 53$ gene and synthesis of p53 mRNA are low in cells in $\mathrm{G}_{0}$ and are induced upon induction with mitogens, with a peak in transcription prior to DNA synthesis and maximal mRNA synthesis during mid-S-phase. This type of response has been suggested to be important for a rapid p53-induced arrest in DNA synthesis in response to DNA damage at a time when cells are synthesizing DNA and thus would be most susceptible to DNA damaging events. In fact, Mosner et al. [20] demonstrated an exceptionally rapid accumulation of active $p 53$ protein in response to DNA damage in synchronized cells populations in mid-S-phase. In this paper, we summarize recent data that describes the mechanism of cell-cycle regulation of the $p 53$ gene and the role that this regulation plays in facilitating the DNA damage response during the $\mathrm{S}$-phase of the cell cycle.

\section{Regulation of p53 Gene Expression during S-Phase of the Cell Cycle}

2.1. p53 Transcription Is Induced during S-Phase. The levels of $p 53 \mathrm{mRNA}$ increase substantially prior to $S$-phase as early as $8 \mathrm{~h}$ after serum stimulation and peak at $18 \mathrm{~h}$ after serum stimulation $[21,22]$. These results are in agreement with earlier publications [18, 20,23].c-myc mRNA levels are also increased by $3 \mathrm{~h}$ after serum stimulation, while no change in the levels of p21 or 14-3-3 $\sigma$ mRNA are detected indicating that while the levels of $p 53 \mathrm{mRNA}$ is increased, there is no evidence for active $p 53$ protein being produced.

The $1.7 \mathrm{Kbp}$ murine $p 53$ promoter has been seen to recapitulate the elevated transcription of the $p 53$ gene when placed upstream of the luciferase [21]. Eighteen hours after transfection, the cells were maintained in serum-depleted medium for $24 \mathrm{~h}$ and then serum stimulated in order to induce S-phase. The $1.7 \mathrm{Kbp}$ promoter decreased in activity after $24 \mathrm{~h}$ of serum depletion with a 4 -fold reduction in expression and demonstrates an induction of promoter activity with maximal promoter activity after $24 \mathrm{~h}$ serum stimulation and entry into S-phase. Analysis of the region required for this induction was ultimately narrowed down to a 20 bp region mapping between -953 and -972 nucleotides upstream of the transcription initiation site $[21,22]$. Database searches for transcription factors that may bind the $p 53$ promoter within this region have provided possible leads as to what protein(s) are binding the promoter within this critical element. Two candidates that have proven to be involved in $p 53$ regulation are $\mathrm{C} / \mathrm{EBP} \beta$ and $\mathrm{RBP}-\mathrm{J} \kappa[21,22]$.

2.2. $C / E B P \beta$. $C / E B P \beta$ is a CCAAT enhancer-binding protein (35) and is critical for the normal growth and differentiation of various cell types [24-26]. Three protein isoforms of $\mathrm{C} / \mathrm{EBP} \beta$ are formed by alternative translation of three inframe initiation sites on C/EBP $\beta$ mRNA [27-29]. C/EBP $\beta$ 1 is the full-length form of the protein $(38 \mathrm{KDa})$ that contains an intact $\mathrm{N}$-terminal transactivation domain and $\mathrm{C}$ terminal DNA-binding domain. C/EBP $\beta-2(35 \mathrm{kDa})$ differs from C/EBP $\beta-1$ by only 21 amino acids at the N-terminus; however, the $\mathrm{N}$-terminal transactivation domain is still functional. Both $\mathrm{C} / \mathrm{EBP} \beta-1$ and $\mathrm{C} / \mathrm{EBP} \beta-2$ are transactivators, although only recently have studies addressed their functional differences. $\mathrm{C} / \mathrm{EBP} \beta-3(21 \mathrm{kDa})$ completely lacks the $\mathrm{N}$-terminal transactivation domain and is thought to repress transcription by complexing with $\mathrm{C} / \mathrm{EBP} \beta-1$ or $=2$ and inhibiting their ability to transactivate target genes [2729].

Electrophoretic mobility shift assays demonstrated binding by endogenous $\mathrm{C} / \mathrm{EBP} \beta$ to the $p 53$ promoter [21]. Anti$\mathrm{C} / \mathrm{EBP} \beta$ antibody, specific for the C-terminal DNA-binding domain, when included in the DNA-binding assays, resulted in a supershift of the bound complex. A C/EBP $\beta$ neutralizing peptide, which blocks the ability of the $\mathrm{C} / \mathrm{EBP} \beta$ antibody to bind, prevented the supershift and demonstrates the specificity of the anti-C/EBP $\beta$ antibody. To assay for C/EBP $\beta$ binding the $p 53$ promoter during the cell cycle, nuclear extracts from arrested and serum-treated Swiss $3 \mathrm{~T} 3$ cells were assayed, and upon growth arrest in $\mathrm{G}_{0}$, there was a decrease in $\mathrm{C} / \mathrm{EBP} \beta$ binding to the promoter. By $3 \mathrm{~h}$ after serum and entry into S-phase stimulation, binding of C/EBP $\beta$ increased substantially and coincides with increased endogenous $p 53$ mRNA levels and an increase in $p 53$ promoter activity at $3 \mathrm{~h}$ after serum stimulation. Finally, it was demonstrated through the use of ChIP assays that $\mathrm{C} / \mathrm{EBP} \beta-2$ binding occurs in vivo in a manner that is similar to the in vitro binding pattern described above [30]. Transfection studies have demonstrated that $C / E B P \beta-2$ activated expression of the p53 promoter upon binding to the identified DNA sequence [21].

2.3. RBP-J $\kappa$. RBP-J $\kappa$ is a $60 \mathrm{kDa} \mathrm{DNA}-$ binding transcription factor that shows a high degree of conservation across species ranging from Drosophila to human [31]. The factor has been shown to be a direct target of the Notch receptor which is central in the regulation of development and differentiation of numerous cell lineages during mammalian development [32-35]. Activation of the Notch receptor results in release of RBP-J $\kappa$ from associated corepressors and the recruitment of coactivators $[33,36,37]$. Thus, in the absence of Notch signaling RBP-J $\kappa$ functions as a transcriptional repressor.

DNA-binding assays performed using nuclear extracts from Swiss3T3 cells that were growing either exponentially, serum depleted for 24 hours, or serum stimulated were employed to test for the presence of RBP-J $\kappa$ by adding an anti$\mathrm{RBP}-\mathrm{J} \kappa$ antibody to the binding reaction. Maximal RBP-J $\kappa$ binding activity is observed after cells are serum starved and arrested in $\mathrm{G}_{0}$ [38]. As p53 mRNA levels start to increase as cells enter S-phase, RBP-J $\kappa$-binding activity to the regulatory site on $p 53$ consistently decreases. This supports the findings that RBP- J $\kappa$ acts as a repressor of $p 53$ transcription, since its binding activity is reduced as cells are released from $\mathrm{G}_{0}$. Finally, it was demonstrated through the use of ChIP assays that RBP binding occurs in vivo in a manner that is similar to the in vitro binding pattern observed. Transfection studies have demonstrated that RBP-J $\kappa$ repressed expression of the $p 53$ promoter upon binding to the identified DNA sequence [38].

The results indicate that at least two transcriptional regulatory proteins bind to the $-972 /-953$ regulatory region on 
the $p 53$ gene and play two very different roles in regulating transcription of this important tumor suppressor. C/EBP $\beta$ 2 serves to enhance $p 53$ transcription during the transition from the growth-arrested state to the entry into S-phase, while RBP-J $\kappa$ serves to repress $p 53$ transcription during this transition. These results suggest that both factors $(\mathrm{C} / \mathrm{EBP} \beta-$ 2 and RBP-J $\kappa$ ) may work cooperatively or in a coordinated manner to help regulate the activity of $p 53$ throughout the cell cycle.

\section{3. p53-Mediated DNA Damage Response in S-Phase}

3.1. p53-Mediated Induction of Bax and p21 in Response to DNA Damage. To investigate the rate of the p53 DNAdamage response as cells enter S-phase, two $p 53$ targets, Bax and $\mathrm{p} 21$, were evaluated by RT-PCR analysis after treatment of cells with camptothecin, a cytotoxic compound which inhibits the DNA topoisomerase I resulting in DNA damage [39]. These experiments showed that both Bax and p21 mRNA levels were induced by 10 to $18 \mathrm{hrs}$ after camptothecin treatment in exponentially growing cells, while the induction of Bax and p21 mRNA expression in cells in S-phase was exceptionally rapid, occurring within 60-90 minutes and remained 3- to 4-fold higher throughout the experiment.

\subsection{Binding of p53 to the Bax Promoter in Response to DNA} Damage. Chromatin immunoprecipitation (ChIP) analysis was performed in order to examine the rate of binding of p53 to the Bax promoter in response to DNA damage [39]. Results of a series of ChIP assays demonstrate that in cells not in S-phase and exposed to camptothecin, the binding of $p 53$ to the Bax promoter remained constant throughout the experiment while in cells entering S-phase, an increase in p53 binding to the Bax promoter is observed after $0.5 \mathrm{hr}$ of drug exposure and continued to increase over four hours. These findings indicate that, in response to camptothecin treatment, Bax levels in cells entering S-phase are expressed in a more rapid manner than in cells that are not in S-phase. In response to DNA damage in cells in S-phase, $p 53$ protein levels increase, bind to the Bax promoter, and cause a more rapid expression of this proapoptotic regulator.

3.3. Apoptosis during S-Phase. The activity of caspases is one useful indicator of apoptosis. Therefore, the activities of two of these proteases, caspases 3 and 7, which are at the end of the apoptotic cascade, were measured in exponentially growing, and in cells entering S-phase after treatment with camptothecin. The activity of caspases 3 and 7 increased between 3 and $6 \mathrm{~h}$ in non-S-phase cells but between 0 and $3 \mathrm{~h}$ in cells both in S-phase. In addition to increasing more rapidly, the overall activity of these two caspases was higher in cells both in early and late S-phase. These findings indicate that apoptosis is induced earlier and to a greater extent in cells subjected to DNA damage during S-phase, during the period of enhanced $p 53$ transcription [39].

DNA fragmentation is also a marker of late-stage apoptosis. Cells were treated with camptothecin and subjected to a TUNEL assay that labels the end of DNA fragments in cells
Increased rapidity of the response of p53 and its targets to DNA damage in exponentially growing versus cells in S-phase

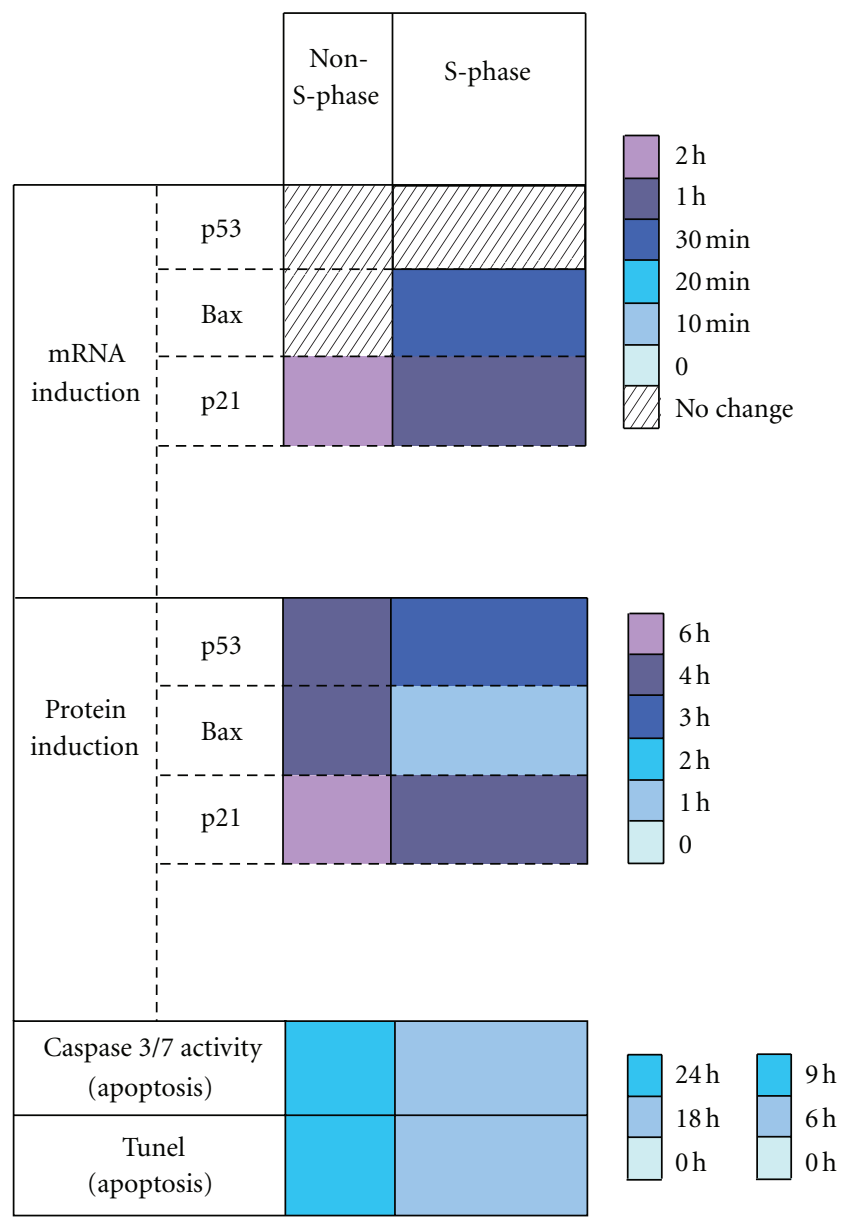

FIGURE 1

undergoing apoptosis. The results of these assays demonstrate that by $18 \mathrm{~h}$ after drug exposure, the number of cells in S-phase with fragmented DNA was signifcantly greater compared to the same time point in non-S-phase cells.

\section{Summary}

p53 induces the transcription of genes that negatively regulate progression of the cell cycle in response to DNA damage or other cellular stressors and thus participates in maintaining genome stability. Under stress conditions, p53 must be activated to prohibit the replication of cells containing damaged DNA. Numerous studies have demonstrated that $p 53$ transcription is activated before or during early Sphase in cells progressing from $G_{0} / G_{1}$ into S-phase via a coordinated expression of two transcription factors, RBP$\mathrm{J} \kappa$ and $\mathrm{C} / \mathrm{EBP} \beta-2$, that act as a repressor and activator of p53 gene expression, respectively, through their binding to the same site on the promoter. In examining the rates of expression of p53 target genes and the rates of entry into apoptosis, evidence has accumulated that indicates that this induction occurs to provide sufficient $p 53$ mRNA to ensure 
a rapid response to DNA damage before exiting S-phase. Figure 1 is a summary of published data illustrating the increase in rate of the p53 response when cells are in S-phase.

\section{References}

[1] M. Oren and J. Bartek, “The sunny side of p53," Cell, vol. 128, no. 5, pp. 826-828, 2007.

[2] K. H. Vousden and C. Prives, "Blinded by the light: the growing complexity of p53," Cell, vol. 137, no. 3, pp. 413-431, 2009.

[3] R. Beckerman and C. Prives, "Transcriptional regulation by p53," Cold Spring Harbor Perspectives in Biology, vol. 2, no. 8, 2010.

[4] F. Toledo and G. M. Wahl, "Regulating the p53 pathway: in vitro hypotheses, in vivo veritas," Nature Reviews Cancer, vol. 6, no. 12, pp. 909-923, 2006.

[5] D. W. C. Li, J. P. Liu, P. C. Schmid et al., "Protein serine/threonine phosphatase- 1 dephosphorylates $\mathrm{p} 53$ at Ser-15 and Ser37 to modulate its transcriptional and apoptotic activities," Oncogene, vol. 25, no. 21, pp. 3006-3022, 2006.

[6] R. Pedeux, S. Sengupta, J. C. Shen et al., "ING2 regulates the onset of replicative senescence by induction of p300-dependent p53 acetylation," Molecular and Cellular Biology, vol. 25, no. 15, pp. 6639-6648, 2005.

[7] H. Zheng, H. You, X. Z. Zhou et al., "The prolyl isomerase Pin 1 is a regulator of p53 in genotoxic response," Nature, vol. 419, no. 6909, pp. 849-853, 2002.

[8] P. Zacchi, M. Gostissa, T. Uchida et al., "The prolyl isomerase Pin 1 reveals a mechanism to control p53 functions after genotoxic insults," Nature, vol. 419, no. 6909, pp. 853-857, 2002.

[9] J. P. Kruse and W. Gu, "SnapShot: p53 posttranslational modifications," Cell, vol. 133, no. 5, pp. 930-e1, 2008.

[10] A. Olsson, C. Manzl, A. Strasser, and A. Villunger, "How important are post-translational modifications in p53 for selectivity in target-gene transcription and tumour suppression?" Cell Death and Differentiation, vol. 14, no. 9, pp. 1561-1575, 2007.

[11] K. H. Vousden and X. Lu, "Live or let die: the cell's response to p53," Nature Reviews Cancer, vol. 2, no. 8, pp. 594-604, 2002.

[12] N. E. Sharpless and R. A. DePinho, "p53: good cop/bad cop," Cell, vol. 110, no. 1, pp. 9-12, 2002.

[13] K. H. Vousden and C. Prives, "P53 and prognosis: new insights and further complexity," Cell, vol. 120, no. 1, pp. 7-10, 2005.

[14] M. B. Kastan and E. Berkovich, "p53: a two-faced cancer gene," Nature Cell Biology, vol. 9, no. 5, pp. 489-491, 2007.

[15] L. Weisz, M. Oren, and V. Rotter, "Transcription regulation by mutant p53," Oncogene, vol. 26, no. 15, pp. 2202-2211, 2007.

[16] S. Strano, S. Dell'Orso, S. Di Agostino, G. Fontemaggi, A. Sacchi, and G. Blandino, "Mutant p53: an oncogenic transcription factor," Oncogene, vol. 26, no. 15, pp. 2212-2219, 2007.

[17] A. M. Goh, C. R. Coffill, and D. P. Lane, "The role of mutant p53 in human cancer," Journal of Pathology, vol. 223, no. 2, pp. 116-126, 2011.

[18] N. C. Reich and A. J. Levine, "Growth regulation of a cellular tumour antigen, p53, in nontransformed cells," Nature, vol. 308, no. 5955, pp. 199-201, 1984.

[19] J. C. Reed, J. D. Alpers, P. C. Nowell, and R. G. Hoover, "Sequential expression of protooncogenes during lectinstimulated mitogenesis of normal human lymphocytes," Proceedings of the National Academy of Sciences of the United States of America, vol. 83, no. 11, pp. 3982-3986, 1986.

[20] J. Mosner, T. Mummenbrauer, C. Bauer, G. Sczakiel, F. Grosse, and W. Deppert, "Negative feedback regulation of wild-type p53 biosynthesis," EMBO Journal, vol. 14, no. 18, pp. 44424449, 1995.

[21] K. Boggs and D. Reisman, "Increased p53 transcription prior to DNA synthesis is regulated through a novel regulatory element within the p53 promoter," Oncogene, vol. 25, no. 4, pp. 555-565, 2006.

[22] K. Boggs and D. Reisman, “C/EBP $\beta$ participates in regulating transcription of the $\mathrm{p} 53$ gene in response to mitogen stimulation," Journal of Biological Chemistry, vol. 282, no. 11, pp. 7982-7990, 2007.

[23] D. Ginsberg, M. Oren, M. Yaniv, and J. Piette, "Proteinbinding elements in the promoter region of the mouse p53 gene," Oncogene, vol. 5, no. 9, pp. 1285-1290, 1990.

[24] P. F. Johnson, "Molecular stop signs: regulation of cell-cycle arrest by C/EBP transcription factors," Journal of Cell Science, vol. 118, no. 12, pp. 2545-2555, 2005.

[25] D. P. Ramji and P. Foka, "CCAAT/enhancer-binding proteins: structure, function and regulation," Biochemical Journal, vol. 365, no. 3, pp. 561-575, 2002.

[26] S. L. McKnight, "McBindall—a better name for CCAAT/ enhancer binding proteins?” Cell, vol. 107, no. 3, pp. 259-261, 2001.

[27] E. M. Eaton, M. Hanlon, L. Bundy, and L. Sealy, "Characterization of $\mathrm{C} / \mathrm{EBP} \beta$ isoforms in normal versus neoplastic mammary epithelial cells," Journal of Cellular Physiology, vol. 189, no. 1, pp. 91-105, 2001.

[28] P. Descombes, M. Chojkier, S. Lichtsteiner, E. Falvey, and U. Schibler, "LAP, a novel member of the C/EBP gene family, encodes a liver-enriched transcriptional activator protein," Genes and Development, vol. 4, no. 9, pp. 1541-1551, 1990.

[29] V. Ossipow, P. Descombes, and U. Schibler, "CCAAT/enhancer-binding protein mRNA is translated into multiple proteins with different transcription activation potentials," Proceedings of the National Academy of Sciences of the United States of America, vol. 90, no. 17, pp. 8219-8223, 1993.

[30] A. Polson, P. Takahashi, and D. Reisman, "ChIP (chromatin immunoprecipitation) analysis demonstrates co-ordinated binding of two transcription factors to the promoter of the p53 tumour-suppressor gene," Cell Biology International, vol. 34, no. 9, pp. 883-891, 2010.

[31] F. Schweisguth and J. W. Posakony, "Suppressor of Hairless, the Drosophila homolog of the mouse recombination signalbinding protein gene, controls sensory organ cell fates," Cell, vol. 69, no. 7, pp. 1199-1212, 1992.

[32] H. Kato, Y. Taniguchi, H. Kurooka et al., "Involvement of RBPJ in biological functions of mouse Notch1 and its derivatives," Development, vol. 124, no. 20, pp. 4133-4141, 1997.

[33] F. Oswald, M. Winkler, Y. Cao et al., "RBP-J $\kappa / S H A R P$ recruits CtIP/CtBP corepressors to silence notch target genes," Molecular and Cellular Biology, vol. 25, no. 23, pp. 10379-10390, 2005.

[34] A. Robert-Moreno, L. Espinosa, J. L. de la Pompa, and A. Bigas, "RBPjkappa-dependent Notch function regulates Gata2 and is essential for the formation of intra-embryonic hematopoietic cells," Development, vol. 132, no. 5, pp. 1117-1126, 2005.

[35] L. Miele, "Notch signaling," Clinical Cancer Research, vol. 12, article $1074 \mathrm{e} 9,2006$.

[36] J. J. D. Hsieh and S. D. Hayward, "Masking of the CBF1/ $\mathrm{RBPJ}(\kappa)$ transcriptional repression domain by Epstein-Barr virus EBNA2," Science, vol. 268, no. 5210, pp. 560-563, 1995.

[37] I. Olave, D. Reinberg, and L. D. Vales, "The mammalian transcriptional repressor RBP (CBF1) targets TFIID and TFIAA to prevent activated transcription," Genes and Development, vol. 12, no. 11, pp. 1621-1637, 1998. 
[38] K. Boggs, B. Henderson, and D. Reisman, "RBP-J $\kappa$ binds to and represses transcription of the 53 tumor suppressor gene," Cell Biology International, vol. 33, no. 3, pp. 318-324, 2009.

[39] P. Takahashi, A. Polson, and D. Reisman, "Elevated transcription of the p53 gene in early S-phase leads to a rapid DNAdamage response during S-phase of the cell cycle," Apoptosis, vol. 16, no. 9, pp. 950-958, 2011. 

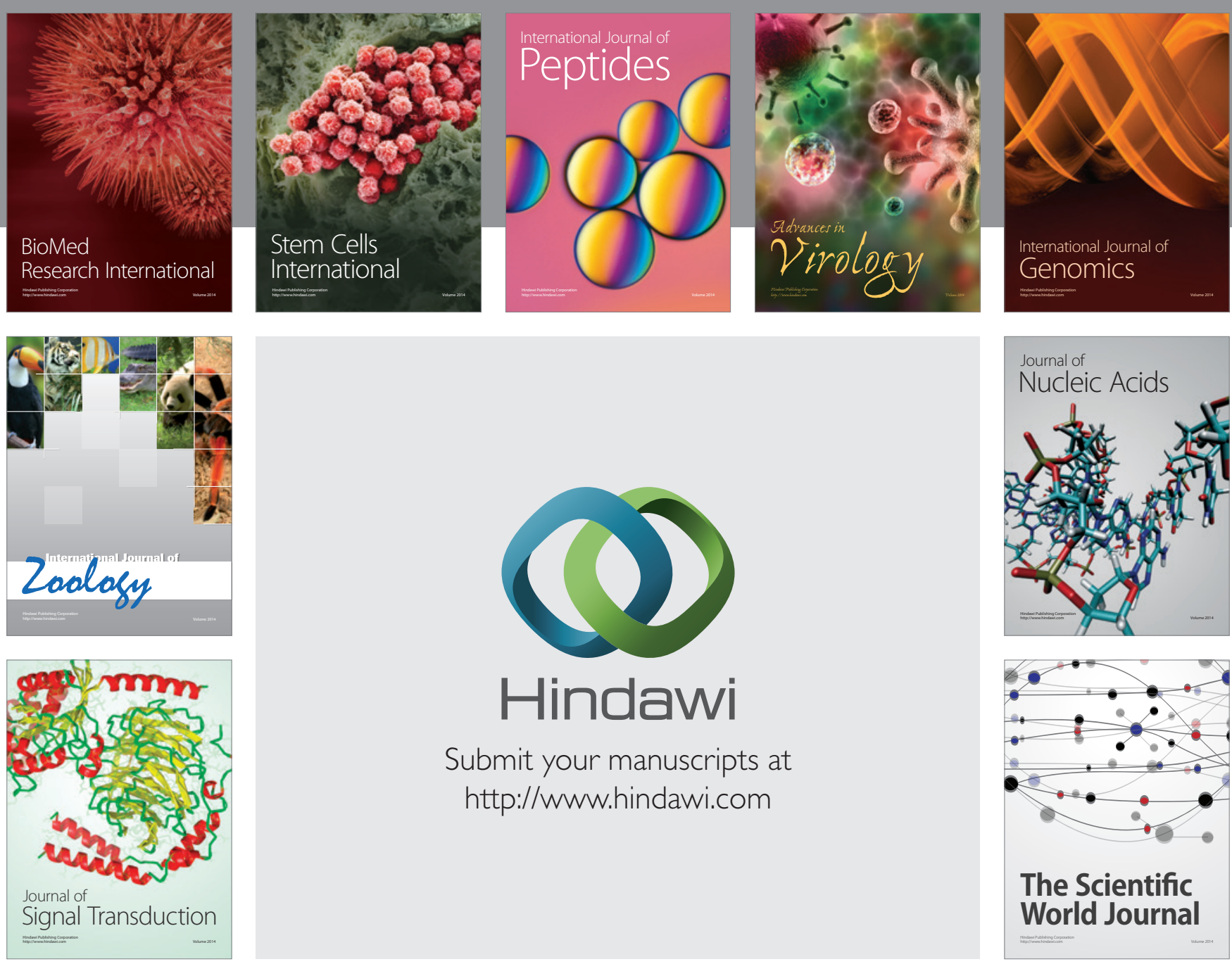

Submit your manuscripts at

http://www.hindawi.com
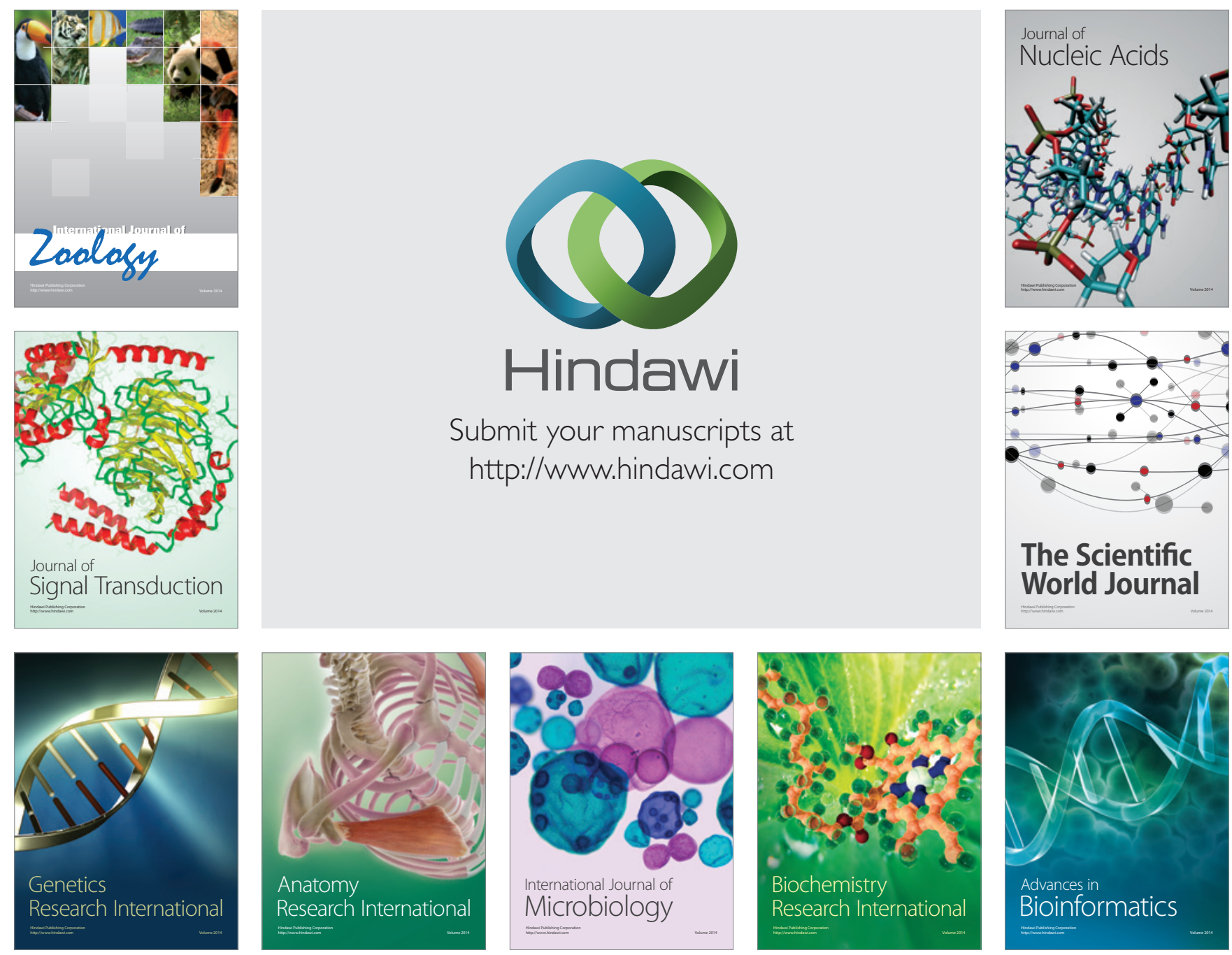

The Scientific World Journal
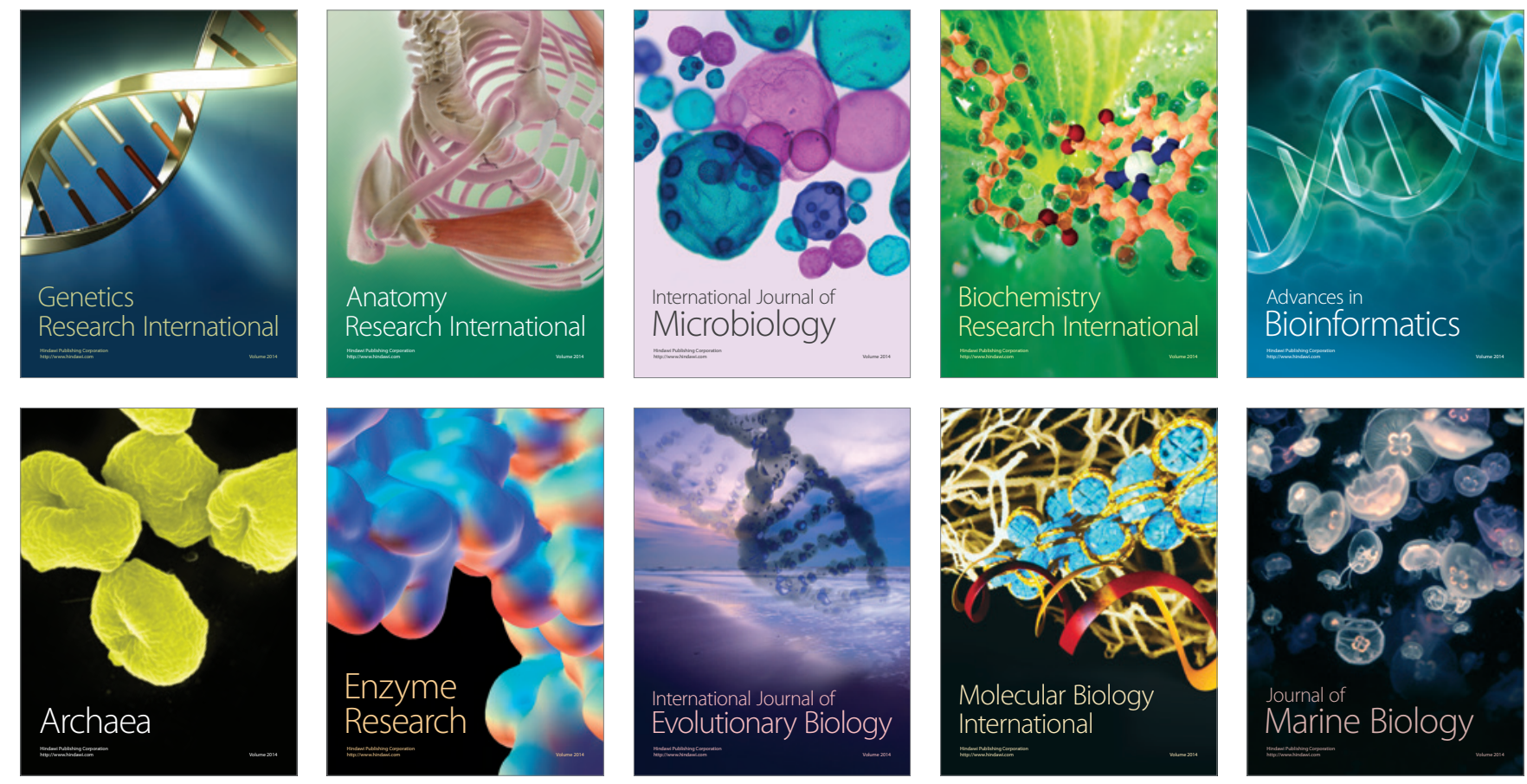